\title{
200 anos da Primeira Biblioteca Pública do Brasil: considerações histórico-biblioteconômicas acerca dessa efeméride ${ }^{1}$
}

\section{Fabiano Cataldo de Azevedo}

\begin{abstract}
Bibliotecário. Professor da Universidade Federal do Estado do Rio de Janeiro. Membro do Polo de Pesquisa sobre Relações Luso-Brasileiras
\end{abstract}

A partir do resultado de um projeto de pesquisa, apresenta considerações acerca da Biblioteca Pública da Bahia. Prioriza uma abordagem histórico-biblioteconômica e, por isso, utiliza um recorte no período de 1811 a 1818, e faz aproximações com práticas biblioteconômicas. Utiliza um corpus de pesquisa composto por documentação primária, compilada a partir no acervo da Fundação Biblioteca Nacional. Objetiva ilustrar a importância de estudos históricos em Biblioteconomia, a fim de compreender descolamentos do passado no presente, de práticas e atividades inerentes ao campo. Conclui que diante dos avanços e de algumas descontinuidades epistemológicas como cientistas, os bibliotecários não podem prescindir de estudos históricos acerca de sua área de conhecimento.

Palavras-chave: Biblioteca Pública da Bahia; História das Bibliotecas; Brasil; Formação e desenvolvimento de coleções.

\section{0 years of the First Public Library in Brazil: library science-historical considerations about the event}

As a result of a research project, the article presents considerations about the Biblioteca Pública da Bahia. A historical approach is used in a period between 1811 and

\footnotetext{
1 Dedico este trabalho à mestra e amiga Ana Virginia Pinheiro, por ter contribuído com o principal dessa pesquisa: a ideia. Agradeço imensamente à Fundação Biblioteca Nacional, pela concessão da bolsa de pesquisa, à Coordenação Geral de Pesquisa, nominalmente à Sra. Eliane Perez; às Divisões de Obras Raras e Manuscritos, cuja competência e atenção de todos os funcionários (estagiários, bolsistas, servidores e terceirizados), foram essenciais para a fluidez do meu trabalho. A todos esses profissionais que compreendem a sua importância para a produção do conhecimento científico: muito obrigado.
} 
1818, and makes comparisons with librarianship practices. A research corpus composed of primary documents in the collection is used which was compiled from the Fundação Biblioteca Nacional. The research aims to illustrate the importance of historical studies on librarianship in order to understand the uncoupling from the past into the present of practices and activities related to the field. It is concluded that in face of the advances and some epistemological discontinuities as scientists, librarians must not ignore historical studies on their area of expertise.

Keywords: Biblioteca Pública da Bahia; The History of the Libraries; Brazil; Formation and collection development.

Recebido em 30.08.2011 Aceito em 02.04.2012

\section{Preâmbulo}

A instituição das Bibliothecas Publicas é uma das mais importantes ações que o progresso humanitário tem realisado, com o fim de promover o desenvolvimento da intelligencia, facilitanto os meios de instrucção as populações, que n'ellas vão encontrar todos os instrumentos de que carecem para o seu aperfeiçoamento intellectual (MUNIZ, 1878, p. 10).

Certamente uma das mais frequentes ponderações acerca das bibliotecas é "como nascem?" ou "como foram formadas?". A pergunta que não gostamos: é "como morre uma biblioteca?" ou "por quê?".

A partir do resultado de um projeto de pesquisa financiado pela Fundação Biblioteca Nacional ${ }^{2}$, este artigo tem o objetivo de narrar alguns fatos sobre a formação da primeira biblioteca pública do Brasil, inaugurada há exatos 200 anos. Assim, tendo como mote a efeméride, pretendemos dar a conhecer a história dos primeiros anos, tendo como ponto de partida o momento no qual quase se extinguiu.

Sabemos que a pesquisa retrospectiva em Biblioteconomia ainda é um campo pouco explorado pelos bibliotecários brasileiros. A História dos Livros $^{3}$ e das Bibliotecas têm sido uma seara mais trilhada por historiadores - com maestria, é verdade. Em nosso campo científico, o que se percebe é uma busca por estudos tecnológicos, disputas epistemológicas e toda sorte de análises que priorizam a discussão, aà luz da bibliografia contemporânea, sem recorrer a estudos e práticas do

\footnotetext{
${ }^{2} \mathrm{O}$ projeto foi submetido ao processo de seleção anual da FBN e teve vigência de julho de 2010 a julho de 2011.

${ }^{3}$ Sobre essa disciplina, recomendamos o já clássico artigo: DARNTON, Robert. O que é a história do livro?: revisitado. ArtCultura, Uberlândia, v. 10, n. 16, p. 155-169, jan.-jun. 2008. Disponível em: http://www.artcultura.inhis.ufu.br/PDF16/R Darnton.pdf. Acesso em: 17 ago. 2011.
} 
passado. Em alguns casos, isso resulta em estudos com pouca consistência, pois temos percebido que, sob a perspectiva de um deslocamento histórico, pode-se localizar caminhos para soluções no presente.

As Bibliotecas Públicas no Brasil passam por um momento tenso, com um notório problema no entendimento de sua missão, função e objetivos. Pouco se discute a formação de suas coleções. Muito mais confusos são os caminhos que perpassam pelo estudo de usuários.

Quando empreendemos um estudo histórico acerca do perfil desse tipo de biblioteca, o que vemos é claramente uma falta de compreensão da linha cronológica dos deslocamentos de significados que ocorreram. Percebe-se que, sobretudo no século XIX, positivista e ainda impregnado de ideias iluministas, a missão que hodiernamente se busca para esse tipo de biblioteca estava claro nos coletâneos, qual seja, "um local de informação, tornando prontamente acessíveis aos seus utilizadores o conhecimento e a informação de todos os gêneros" ${ }^{4}$.

Nosso objeto é a Biblioteca Pública da Bahia (BPB) e a ambiência é a sociedade soteropolitana da primeira metade do século XIX, momento no qual se acreditava que o Brasil entrava em uma "Idade d'Ouro". Não pretendemos aqui, analisar em minúcias aspectos da história social desse período, faceta que deixaremos aos colegas historiadores que, com melhor competência, poderão fazê-lo.

Anuímos à afirmação de Deaecto (2011) acerca do interesse do livro, como objeto de pesquisa nesse início de XXI, pois parece estar cada vez mais claro que diante das mudanças no campo editorial que estamos presenciando, é mister compreender os deslocamentos históricos desse objeto ${ }^{5}$.

O recorte cronológico da pesquisa situa-se primordialmente entre os anos de 1811 a 1818 , ou seja, ano de fundação e data de um catálogo manuscrito da Instituição que se constitui em um documento, no conceito de Le Goff $(2010)^{6}$, mas igualmente um local de memória, seguindo Nora $(1993)^{7}$. O acervo original não existindo mais, o catálogo se torna o único instrumento de rememoração da coleção que foi tão exaltada pelos que tiveram a oportunidade de consultá-la. Ainda no que concerne ao nosso recorte de pesquisa, justificamos porque identificamos nele, como período fundador, a estruturação da Instituição. De certo que, como é habitual em pesquisas desse mote, em alguns momentos, serão necessárias algumas incursões a períodos que vão além do estabelecido pela investigação, com objetivo de ilustrar certos desdobramentos.

\footnotetext{
4 IFLA. UNESCO. Manifesto da IFLA/UNESCO sobre Bibliotecas Públicas. 1994. Disponível: $<$ http://archive.ifla.org/VII/s8/unesco/port.htm. >. Acesso em: 5 jan. $2009 \mathrm{Em}$ absoluto é nosso interesse aqui fazer qualquer estudo comparativo sobre a Biblioteca Pública hoje e no passado.

${ }^{5}$ Entendemos o livro como objetivo de investigação a partir da ideia desenvolvida por Maria Beatriz Nizza da Silva, em: SILVA, M. B. N. da. Produção, distribuição e consumo de livros e folhetos no Brasil colonial. Revista do Instituto Histórico e Geográfico Brasileiro, v. 314, p. 78-94, jan./mar. 1977.

6 Le Goff, em "Documento/Monumento" considera que alguns materiais "podem apresentar-se duas formas principais: os monumentos, herança do passado, e os documentos, escolha do historiador". Nesse catálogo, temos uma recolha de outros documentos que sedimentam e legitima o passado da Biblioteca Pública da Bahia. ${ }^{7}$ Temos em Nora (1993, p. 13) a seguinte ideia: "os lugares de memória nascem e vivem do sentimento que não há mais memória espontânea, que é preciso criar arquivos, que é preciso manter aniversários [...]".
} 
A Biblioteca Pública da Bahia foi criada "graças ao espírito associativo da elite baiana" (SILVA, 2008, p. 6), sob influência do espírito iluminista. Sua importância para estudos nas áreas de História e Letras contrasta com a escassez quase absoluta de pesquisas sobre essa Biblioteca.

No âmbito da História, abundam pesquisas sobre a circulação e consumo de livros no Brasil colônia ${ }^{8}$, todavia, poucos privilegiaram a história da Biblioteca Pública da Bahia.

A pioneira, no tema - a crer pelo nosso levantamento bibliográfico foi a historiadora luso-brasileira Maria Beatriz Nizza da Silva, no artigo $A$ Livraria Pública da Bahia em 1818: obras de história, publicado pela Revista de História em 1971. Nesse trabalho, a pesquisadora analisou o catálogo manuscrito, cotejando os livros de história. Anos depois, a pesquisadora Moema Parente Augel, em sua dissertação Visitante estrangeiros na Bahia oitocentista (1975), trouxe valiosas informações sobre o acervo da biblioteca nos primeiros anos de sua fundação. Rubens Borba de Morais, em Livros e Bibliotecas no Brasil Colonial (1979; 2006), dedicou um capítulo inteiro, revelando informações crucias. O profícuo Wilson Martins, nos anos de 1980, em A palavra escrita: história do livro, da imprensa e da biblioteca (2001) tratou da Livraria no capítulo sobre as bibliotecas brasileiras. Laurence Hallewell, em O livro no Brasil (1982; 2005), cita a Biblioteca ao tratar da Manuel Antônio da Silva Serva - isso para citar os mais significativos.

Além desses estudos, a BPB só apareceu citada em alguns parágrafos ou páginas de trabalhos acadêmicos, como no recente artigo de Luiz Antônio Gonçalves da Silva, Bibliotecas brasileiras vistas pelos viajantes no século XIX (2010).

Por este panorama, podemos justificar a relevância de uma pesquisa, que teve dentre seus objetivos recuperar e mapear fontes históricas sobre essa importante biblioteca e, a partir dai, buscar uma análise sob a luz da Biblioteconomia.

A ideia de "fénix"9, associada à Biblioteca Pública Bahia, leva em consideração sua história. De fato, por duas vezes, essa biblioteca passou por uma espécie de quase morte e ressurgiu como Instituição, como um marco de um projeto que refletiu os ideais iluministas da sociedade soteropolitana do século XIX.

Acerca do uso "Livraria" e "Biblioteca", devemos aqui estabelecer algumas considerações. Nos documentos da época, o uso se faz como

\footnotetext{
${ }^{8}$ Indicamos as leituras de duas fontes que trazem um ótimo panorama da produção da historiografia nacional sobre o tema: VILLALTA, L. C. A história do livro e da leitura no Brasil Colonial: balanço historiográfico e proposição de uma pesquisa sobre o Romance. Convergência Lusíada, Rio de Janeiro/Real Gabinete, v. 21, p. 165-185, 2005. Disponível em: <http://www.caminhosdoromance.iel.unicamp.br/estudos/ensaios/livroeleitura.pdf>. Acesso: 20 maio 2010; e DEAECTO, M. M. Introdução. In:__. O império dos livros: instituições e práticas de leitura na São Paulo oitocentista. São Paulo: Edusp; Fapesp, 2011. p. 23-35.

${ }^{9} \mathrm{O}$ título de nosso projeto submetido à FBN foi "Livraria Pública da Bahia: a biblioteca fênix dos trópicos, 1811$1818^{\prime \prime}$.
} 
sinônimo e, de fato, assim o era. No Vocabulário Portuguez e Latino (1728), de Raphael Bluteau, "livraria" é definida como "lugar onde estão muitos livros em estantes. Bibliotheca. Vid. Bibliotheca. Vid. Livro". E "biblioteca" é descrita como: "Bibliotheca. Livraria" (BLUTEAU, 1728, p. $118,163)$. No Diccionario da lingua portuguesa (1813), de Antonio de Moraes Silva, o termo "livraria" é conceituado com: "Bibliotheca, casa, ou estantes, onde estão os livros. Collecção de Livros" e para o termo biblioteca: "Collecção de Livros posta em estantes, ou armários" (MORAES SILVA, 1813, p. 280, 322).

Por essas razões, manteremos, nas transcrições - feitas respeitando a grafia da época - os termos como aparecerem, justificando, ainda, o uso do termo "biblioteca" no título deste artigo.

Este artigo tem como escopo historicizar, com base na documentação primária que levantamos, parte da história da Biblioteca Pública da Bahia, portanto, pouco se discutirá o tema à luz de outros autores. Não obstante, seguiremos uma linha teórica alicerçada nos autores supracitados - que abordaram nosso objeto de pesquisa. No âmbito da Biblioteconomia, Campello (1988); Rebelo (2002); e Pinheiro (2007), foram nossas bases para compreender a tipologia da Biblioteca Pública nos dias atuais; já em Lasso de la Vega (1952); Prado (1992); e Maciel e Mendonça (2000), percebemos como essas organizações se estruturam. Esses autores, apesar de modernos, contribuíram para mapearmos o modus faciendi da biblioteconomia no passado, mesmo que prática e conceito não existissem.

A literatura biblioteconômica possui um corpus teórico retrospectivo pouco utilizado e conhecido. Para evitarmos os anacronismos, lançamos mão de Naudé (1627); Peignot (1828); Cousin (1882); Petzholdt (1894); e Cim (1902). Todos esses autores (outrora presença constante na bibliografia dos cursos de Biblioteconomia) fazem parte da nossa filiação teórica, pois fundamentam nossa compreensão acerca dos aspectos da organização e administração de bibliotecas no passado.

Assim, pretendemos, nesse artigo, apresentar um histórico sobre a fundação da Biblioteca Pública da Bahia, privilegiando as motivações para criação e a formação do acervo no período de 1811 a 1818. Para isso, utilizaremos um corpus de pesquisa formado, essencialmente, por documentação localizada e compulsada no acervo da FBN.

O historiador Peter Burke (1997, p. 48) pondera que "para se compreender a história é necessário saber mergulhar sob as ondas", mutatis mutandis, o que esse artigo reflete.

\section{0 morrer e ressurgir da Biblioteca Pública da Bahia}

A 1 hora da tarde, exacta, o forte de S. Marcello, disparou dois tiros de canhão, pólvora secca, alarmante signal [...]. Logo os primeiros tiros que atingiram os edifícios do Palácio do Governo, Intendência e Theatro São João, produzindo-Ihes estragos [...]. Rapidamente o fogo se propagou, attingindo os 
compartimentos onde eram installados a diretoria de terras e minas, Biblioteca Pública e salão nobre [...]. O Jornal de Notícias considera entre as conquencias deplorabilissimas do bombardeio a perda da nossa preciosa Biblioteca Pública [...]. Tinha mais de trinta mil volumes, em cujo numero obras raríssimas pelo assumpto, pela data de publicação e pela qualidade da edição, colleções de jornaes os mais antigos do paiz e autographos e documentos do maior valor. É um verdadeiro desastre irreparável a sua perda [...] (SÁ, 1918, p. $\left.667-668^{10}\right)$.

A longa e dramática (e necessária) citação, ilustra o fim de um grande sonho de ilustração nos trópicos ${ }^{11}$.

O bombardeio autorizado pelo presidente Hermes da Fonseca, no dia 10 de janeiro de 1912, à cidade de Salvador, causou o que chamamos da primeira morte da primeira Biblioteca Pública do Brasil, um ano após festejar seu centenário. Uma biblioteca cujo fundo de formação contou com doações de livros dos mais ilustres letrados da Bahia - muitos deles egressos da Universidade de Coimbra.

A máxima usada por Battles (2003, p. 157), para falar das perdas universais de grandes bibliotecas, também pode ser transposta para nossa realidade, pois ele considera que "se o século XIX caracterizou-se pela construção de bibliotecas, o século XX ficou marcado por sua destruição".

Todo o esforço de Pedro Gomes Ferrão Castelo Branco, Alexandre Gomes Ferrão e Francisco Agostinho Gomes para elaborar o plano da Biblioteca e guarnecê-la de bons livros, viu-se arruinado em questão de duas horas.

Segundo relatos, à época, o acervo contava com cerca de 60.000 volumes. Além dos livros, perderam-se todos os periódicos, dentre os quais o periódico Idade d'Ouro do Brazil (MOTTA; SILVA, 1958). De acordo com o mesmo autor, o que o fogo não lambeu, os saques que seguiram terminaram o trabalho.

Em 04 de dezembro de 1961, o prédio da Imprensa Oficial na praça Municipal de Salvador, sofreu um incêndio e, como ficava perto da BPB, essa também foi atingida, tendo algumas coleções de periódicos e livros destruídos.

De acordo com a documentação, não foi possível estabelecer o volume da perda do primeiro incêndio, sem dúvida o mais significativo. Todavia, não é uma investigação de todo impossível. Seja como for, a Biblioteca Pública da Bahia, mais uma vez, ressurge nos anos de 1970, no prédio que até os dias atuais ocupa, no bairro dos Barris.

\footnotetext{
${ }^{10}$ Também citado por MOTTA e SILVA, B. Cidade de Salvador: caminho e encantamento. São Paulo: Companhia Editora Nacional, 1958. p. 359.

${ }^{11}$ Seria impossível contar a história da Biblioteca Pública da Bahia sem mencionarmos esse fato marcante. Por isso, optamos por uma invenção na narrativa, ou seja, contar a história de trás para frente. Nosso argumento baseia-se no fato que podemos considerar - metaforicamente, também - um novo ressurgir a produção de pesquisas que tomaram/tomem como base as fontes primárias que revelavam a história dessa Instituição.
} 


\section{A Livraria Pública da Bahia: breves apontamentos da fundação e histórico}

Un établissemet três remarquable à Bahia est celui d'une bibliothèque publique. Il est dû à I'active administration de $\mathrm{M}^{\mathrm{r}}$ le comte dos Arcos. Ce n'est encore qu'une faible collection d'environ 4000 volumes, mais tous les ouvrages sont assez bien choisis. On n'y voit point de ces effrayants colosses d'infolios théologiques et mystiques qui forment les plus imposants soutiens des bibliothèques de couvent. Il est bien flatteur pour un Français de vérifier que 3000 volumes au moins son écrits dans sa langue. (TOLLENARE, 1817 apud MORAES, 2006, p. 157).

Apesar de um estilo hiperbólico do viajante francês Tollenare, essa citação destaca algumas características importantes do acervo da BPB.

A Biblioteca Pública da Bahia tem uma "pré-história" que precisa ser contextualizada, a fim de se compreender os meandros que evolvem a História do Livro na Bahia ${ }^{12}$. Particularmente relutamos em concordar com Hallewell (2005, p. 145), quando afirma que "os projetos de um jornal e de uma biblioteca pública [em Salvador] eram ambos, claras tentativas de competir com o Rio de Janeiro".

Salvador era uma capital que convivia com livros, de certo, muito antes que o Rio de Janeiro. Foram os soteropolitanos que estabeleceram movimentos literários, como a Academias dos Esquecidos (1729) e dos Renascidos (1759), muito decorrente de um grande número de egressos das universidades portuguesas, principalmente Coimbra, que tinha uma forte característica iluminista.

Moraes (2006) informa que mesmo um ano antes da fundação da BPB, os estatutos da "Real Sociedade Baiense de Homens de Letras" previa uma biblioteca. Por esse brevíssimo apanhado histórico, é possível perceber que os cidadãos soteropolitanos não eram alheios aos livros. Havia, portanto, naquela capital, gens de lettres e uma ambiência intelectual que os permitiram pretenderem uma biblioteca.

Clado Ribeiro Lessa, no artigo As bibliotecas brasileiras dos tempos coloniais: apontamentos para um estudo histórico, publicado em 1946, afirma que "quanto a livrarias particulares na Baía temos conhecimento de diversas através dos autos de apreensão dos bens das pessoas comprometidas na conjuração de 1798" (LESSA, 1946, p. 344).

Além desses particulares, havia duas bibliotecas de grande valor, a do Mosteiro de São Bento e do Colégio dos Jesuítas. A respeito dessa

12 Recomendamos a leitura: ARAÚJO, J. de S. O perfil do leitor colonial. Revista de Cultura Vozes, v. 4, p. 448-450, Petrópolis, 1989. Consideramos, ainda, igualmente valiosos, para compreender a ambiência cultural de Salvador no século XIX, alguns trabalhos produzidos pela Profa. Kátia Mattoso Carvalho. 
última, sabe-se que era uma das mais importantes dos inacianos no Brasil. Em 1759, a Companhia de Jesus foi expulsa de Portugal e dos seus reinos. Um pouco mais de dez anos depois, por volta de 1775, supõe-se que "os livros da Biblioteca do Colégio da Baía deveriam andar por 15.000" (SERAFIM LEITE, 1945, p. 214). Todavia, infelizmente, segundo Afrânio Peixoto, esses livros estavam "entregues às traças pelo desmazelo, como a Igreja e o Colégio, quase arruinado, no fim do XVIII" (PEIXOTO, 1946, p. 250).

Seguindo os relatos que perquirimos, alguns informam que quando procuraram um local para nova Instituição, a opção recaiu sobre o espaço onde, no passado, habitou a melhor biblioteca da cidade - que não deixa de ter um sentido fortemente simbólico. A despeito de algumas fontes deixarem a dúvida se o acervo a BPB incorporou à sua coleção volumes da antiga livraria dos jesuítas, nesse primeiro momento da pesquisa, não foi possível apurar esse dado, apesar da factibilidade.

\subsection{As motivações para a fundação}

A ideia de fundação da Biblioteca Pública da Bahia foi "devida ao prestante Bahiano Coronel Pedro Gomes Ferrão e foi mandada por em execução pelo Exmo Conde dos Arcos, então Governador da Provincia" (BIBLIOTECA Pública da Bahia, s. d.). O mesmo documento relata que o coronel foi o primeiro diretor da Biblioteca e responsável por uma avultada doação de três mil volumes de "diversas obras".

Após a morte do Conde dos Arcos, assumiu o lugar de diretor Francisco Agostinho Gomes ${ }^{13}$, um homem "riquíssimo e o espírito mais iluminado da cidade pelo saber, conhecedor do francês e do inglês, "ledor infatigável, e a par de todo o movimento científico do mundo" (LESSA, 1946, p. 339).

Na sequência da aprovação para o estabelecimento da tipografia de Manoel Antonio da Silva Serva ${ }^{14}$, no dia 26 de abril de 1811, o coronel Pedro Gomes Ferrão Castelo Branco apresentou o Plano para 0 estabelecimento de uma bibliotheca pública na cidade de Salvador, oferecido a aprovação do Sr. Conde dos Arcos, capitão general daquela capitania ${ }^{15}$, para a criação de uma biblioteca em Salvador. A motivação para a criação da Biblioteca fica patente no início do texto:

\footnotetext{
13 A respeito da biografia de Francisco Agostinho Gomes, recomenda-se: NEVES, L. M. B. P. das; NEVES, G. P. das. A Biblioteca de Francisco Agostinho Gomes: a permanência da ilustração luso-brasileira entre Portugal e o Brasil. Rev. IHGB, Rio de Janeiro, n. 425, out./dez. 2004. NEVES, L. M. B. P. Luzes nas Bibliotecas de Francisco Agostinho Gomes e Daniel Pedro Muller: dois intelectuais luso-brasileiros. CONGRESSO INTERNACIONAL ESPAÇO ATLÂNTICO DE ANTIGO REGIME: PODERES E SOCIEDADES, 2005, Lisboa. Anais... Lisboa: Centro de História de Além-Mar, 2005. Disponível em: <http://cvc.institutocamoes.pt/eaar/coloquio/comunicacoes/lucia maria bastos neves.pdf. >, Acesso em: Acesso: 20 maio 2010. ${ }^{14}$ Infelizmente não podemos, por questão do foco deste artigo, detalhar informações acerca da Tipografia Silva Serva. Assim, além dos trabalhos - indicados abaixo - dos professores Cybelle e Marcello de Ipanema, recomendamos, também, SILVA, M. B. N. da. A imprensa periódica na época joanina. In: NEVES, L. M. B. P. das . Livros e impressos: retratos dos setecentos e dos oitocentos. Rio de Janeiro: EdUerj, 2010. p. 16-30.

${ }^{15}$ Esse documento consta reproduzido no Correio Brazilense, v. 7, n. 39, p. 219-233, ago. 1811. Disponível na FBN Digital: <http://objdigital.bn.br/acervo digital/div periodicos/correio braziliense/volume07.pdf.>. Essa informação foi pela primeira vez citada por Borba de Moraes $(1979,2006)$. Pode-se ler o documento ainda no original e microfilme sob a guarda da Divisão de Obras Raras da FBN.
} 
Padece o Brazil, e particularmente essa Capital, a mais absoluta falta d'meios para entrarmos em relação de idéias com os Escriptos da Europa, e para se nos patentearem os thesouros do saber espalhados nas suas obras, sem as quaes nem se poderão conservar as ideias adquiridas, e muito menos promovidas a beneficio da sociedade.

Na citação, destacam-se ideias expressamente iluministas, que viam a promoção da instrução e acesso ao livro como um meio de progresso.

Este certamente é um dos substratos pelo qual podemos entender a relação da fundação da Typografia Silva Serva e abertura da BPB. Para os cidadãos soteropolitanos, uma biblioteca e uma tipografia possuíam imbricamentos que corroborariam para levar as Luzes àquela capital e, como consequência, ao Brasil. Essa perspectiva, também visível no texto memorialístico de Antonio Muniz Sodré de Aragão, publicado em um catálogo da Biblioteca de 1878:

Os factos que commemora a epocha da gloriosa administração do Conde dos Arcos são em numero innumeravel, durante esse brilhante periodo a imprensa foi introduzida no Brazil e concedida a permissão para o estabelecimento da primeira typographia que na Bahia começou a publicação da Idade d'Ouro que em seu nome symbolisava a nova era aberta pelo progresso às aspirações progressivas que agitava o paiz; inaugurou-se a Bibliotheca publica; [...] inaugurou-se 0 Theatro de S. João no dia do aniversário natalicio do Monarcha [...] $\left(\mathrm{MUNIZ}^{16}, 1878\right.$, p. 418).

Voltando ao Plano. No dia 30 do mesmo mês foi aprovado, deliberou-se, no mesmo documento, que fosse escolhido, dentre os censores da tipografia de Silva Serva, o diretor na nova Instituição. O censor seria responsável por todas as medidas administrativas do plano "não só da execução de todas as medidas mencionada n'aquelle plano, mas tambem da direcção de todos os objectos e trabalhos intermediarios até à perfeição d'aquelle excellente estabelecimento" (MUNIZ, 1878, p. 321) ${ }^{17}$.

Por um Aviso de 25 de junho, ainda do mesmo ano, o Governo Geral aprovou a deliberação de Conde dos Arcos, que autorizou que o Plano fosse impresso a 8 de maio de 1811. Como seria esperado, saiu da tipografia de Silva Serva em quatro páginas.

A respeito do dia da inauguração, Moares (2006, p. 155) é única fonte que cita a solenidade de 13 de maio. Segundo o autor:

pensou-se em inaugurar a biblioteca no dia do aniversário do príncipe regente, na sala da antiga livraria dos jesuítas, no Terreiro

16 À guisa de esclarecimento ao leitor: este catálogo foi organizado pelo então bibliotecário Antonio Ferrão Muniz. No conteúdo, consta um texto de seu pai, Antonio Muniz Sodré de Aragão.

17 Officio do Conde dos Arcos de 30 de Abril de 1811. Documento transcrito no Catálogo de 1878. 
de Jesus, mas isso não foi possível tal o estado de ruínas em que se encontrava. Resolveu-se então utilizar a sala do dossel do palácio do governador para, na cerimônia habitua de 13 de maio, comemorar juntamente a fundação da tipografia, o aparecimento da gazeta Idade d'Ouro e a biblioteca [...].

Antonio Muniz Sodré de Aragão menciona que "o sr. Ignacio Accioli, nas Memorias Historicas e Politicas da Provincia da Bahia, diz que foi no dia 13 de Maio, preferimos porém a data que designamos, porque é a que indica a carta de Pedro Gomes" (MUNIZ, 1878, p. 11). Seja como for, o silêncio nos documentos analisados pode indicar que no natalício de $D$. João VI tenha ocorrido apenas um ato solene, mas não abertura de fato.

No mesmo documento citado acima, Aragão relata que a BPB foi inaugurada com solenidade no dia 4 de agosto de 1811, no segundo pavimento do edifício que havia pertencido aos jesuítas no Terreiro de Jesus, "ao lado do mar para onde tem hum excellente golpe de vista" (MUNIZ, 1878, p. 10). No ato solene, Pedro Gomes Ferrão Castelo Branco fez um discurso ${ }^{18}$, que posteriormente foi impresso por Silva Serva, reproduzido no Investigador Portuguez de Março de 1812 e no Catalogo Geral das Obras de Sciencias e Litteratura que contem a Bibliotheca Publica da Provincia da Bahia, em 1878.

Em seu discurso, Pedro Gomes Ferrão, como homem do seu tempo, evidencia a questão das Luzes em Salvador. Para ele, a mercê - que ele chama de "socorro" - já concedida aos cidadãos da corte do Rio de Janeiro" ${ }^{19}$, levaria a "circunstancias tambem favoraveis á Instruç̧ão dos Habitantes do Brazil". Sem a instituição de uma Biblioteca Pública e uma Tipografia, de acordo com sua ponderação, "seria impossivel, não digo só, fazerem-se progressos, até darem-se com segurança os primeiros passos em qualquer dos immensos ramos das Artes, e Sciencias".

O primeiro diretor da BPB deixa absolutamente claro que posição de que a Tipografia e Biblioteca estão associadas a qualquer ideal de "Luzes". Pondera que:

felizmente, que por meio da Estampa, e da Typographia, as Descobertas, Invenções, e Melhoramentos no vasto Mappa do saber Humano, podem facilmente reunir-se em Bibliothecas, d'onde como de pura Fonte saião a fertilisar os nossos Campos, a polir os nossos costumes, e a promover todas as virtudes, que constituem o Cidadão honrado, Benemerito do Soberano, e da Patria (MUNIZ, 1878, p. 47).

Ferrão prescindiu de comparar o Brasil com a Europa e traçou um paralelo com os feitos para instrução que estava em andamento nos Estados Unidos, que, para ele, faz parte do rol de "paizes não menos

\footnotetext{
18 A FBN possui exemplar do "Discurso". Localização: 060,003,004a. Microfilme: OR-00049 (01).

${ }^{19}$ Refere-se aqui ao fato de que, em 1808, houve a instalação da Impressa Régia no Rio de Janeiro.
} 
novos, e incultos como o nosso". E destaca os sucessos que a criação de uma Biblioteca Pública trouxe àquele país:

A America Ingleza, onde huma grande parte dos Habitantes inteiramente attenta a objectos d'interese immediato, mal podia lembrar-se de applicações literarias, e o pequeno numero d'aquelles, que tinhão inclinação aos estudos, não podião satisfazer, por falta de Livrarias, em cercunstancias bem analogas às nossas, considerou como hum successo summamente importante, e util 0 Estabelecimento da sua primeira Bibliotheca publica (MUNIZ, 1878, p. 47).

Seu discurso também revela a importância/missão de uma Biblioteca Pública naqueles primeiros anos do século XIX, instituídas, em suas palavras, por "Póvos Illuminados". Essas instituições representavam um "ponto de reunião aos Amadores das Artes, e Sciencias: conferindo em comum sobre as suas duvidas, communicando os seus pensamentos [...]". Era um espaço privilegiado de sociabilidade e de circulação de ideais, onde seus frequentadores "elles fazem progressos, que jamais se poderião ter conseguido na reclusão dos Gabinetes, e privação de taes socorros" (MUNIZ, 1878, p. 50). O produto dessas ideias imiscuídas com as leituras e com a sociabilidade constituíam, segundo Castelo Branco, no "germen de quasi todas as descobertas, são como o ar, que se respira, sem pensarmos, e a que devemos a vida".

Essa mesma anima pode ser apreciada nas notícias da fundação da biblioteca. Exaltando a chegada as Luzes na cidade de Salvador e a importância para a cultura nacional e revelando a ambiência intelectual, o Idade d'Ouro do Brasil2 ${ }^{20}$, de 6 de agosto de 1811, relatou:

Domingo 4 do corrente se fez a abertura solemne da Livraria desta Cidade na mesa casa, que foi Livraria do Collegio dos proscriptos Jesuitas. A presença do Excellentissimo Senhor Conde dos Arcos nosso amavel Governador deu o maior lustre a este acto brilhantissimo pela deliciosa situação da sala, que elevada na eminencia da Cidade, e do edificio do Collegio domina esta Bahia; pelo concurso de pessoas de todas as Ordens; e pelas doces esperanças de melhoramento, que prognostica a diffusão das luzes. Conhecimentos de todos os generos postos ao alcance de todos os curiosos hão de excitar os talentos até agora amorrecidos, e a Bahia no Zenith de sua gloria abençoara perpetuamente os dias verdadeiramente d'ouro desta não pensada regeneração. Neste occasião recitou como IPANEMA, M. de; IPANEMA, C. de. História da Comunicação: notas. Brasília, DF: Editora da Universidade de Brasília, 1967. (Série Comunicação Coletiva). Recomenda-se, também: IPANEMA, M. de; IPANEMA, C. de. A tipografia na Bahia: documentos sobre suas origens e o empresário Silva Serva. 2. ed. Salvador: EDUFBA, 2010. SILVA, M. B. N. da. A primeira Gazeta da Bahia: Idade d'Ouro do Brazil. Salvador: EDUFBA, 2011. A primeira edição desse livro saiu pelo INL em 1978 e a segunda também pela EDUFBA em 2005. Além do livro, há: SILVA, M. B. N. da. A imprensa periódica na época joanina. In: NEVES, L. M. B. P. das. Livros e impressos: retratos do setecentos e do oitocentos. Rio de Janeiro: EdUerj, 2009. p. 15-29.
} 
o Coronel Pedro Gomes Ferrão Castel-Branco huma elegantissima oração, em que se notava erudição escolhida, e a literatura vasta com profundas reflexões adequadas às circunstâncias, e actual situação politica do mundo. Todos os dias á execpção das Quartas feiras estará a Livraria patente a todas as pessoas de qualquer condição.

Um ano depois, já com o reflexo da fundação, o Investigador Português de março de 1812, noticiou a inauguração da Biblioteca nos seguintes termos:

se já tivemos o gosto de annunciar em nosso Jornal o plano para o estabelecimento de huma Bibliotheca Publica na Cidade da Bahia, temos hoje o redobrado prazer de publicar, que hum Estabelecimento tão util, e que tanta honra faz ao zelo, actividade, e patriotismo do Governador, e Capitão General daquella Capitania o Exm. Conde dos Arcos, a todos os habitantes da Bahia em geral, e em particular o zeloso, e esclarecido redactor daquelle Plano - o sr. Pedro Gomes Ferrão Castello; hum Estabelecimento tão util, dizemos nós, se acha já em pratica desde o dia 4 de Agosto proximo passado. O Despota ama a ignorancia, e o erro; persegue, e detesta as luzes; um Principe Legitimo, Justo e que só faz consistir sua gloria na felicidade de seos vassallos, detesta a ignorancia, e o erro; ama, e protege as luzes, porque sabe que sem ellas não pode haver civilisação, nem prosperidade, nem verdadeira moral, nem costumes. Não era, pois possivel que S. A. R. deixasse de approvar tão util Instituição: approvou-a: não se contentou com preciosos, e animadores elogios: deo o Collegio que foi dos jezuitas, o qual tem a necessaria capacidade, e precisas commodidades para hum vasto Estabelecimento desta natureza. No dia 4 de Agosto se fez a abertura da Caza com o Discurso que vamos transcrever, e que achamos mui digno, e appropriado ao assumpto, e occazião; e naquelle mesmo dia se declarou Publica, a Bibliotheca, que já conta acima dos quatro mil volumes, e começou a ser franqueada pelas Pessoas amigas da Literatura, e Sciencias ${ }^{21}$.

Em ambos os textos, fica muito evidente a recorrência que aparecem enunciados que representam o iluminismo e o positivismo e, ainda, os ideais civilizatórios (ELIAS, 1994) comuns a esse período. O próprio fundador do Idade d'Ouro do Brazil, o português Manuel Antonio da Silva Serva, aliava-se a esses pensamentos.

Essa elite intelectual baiana, reflexo das Luzes Luso-Brasileiras, estava preocupada com o desenvolvimento científico do Brasil. Havia neles um sentimento de grupo imbuído pelo dever, dentro de um contexto

\footnotetext{
${ }^{21}$ Acervo: FBN.
} 
civilizatório $^{22}$, de oferecer as luzes a toda a população. Para eles, era claro a relação entre os livros - apesar da censura - já autorizados a serem impressos e uma Biblioteca Pública.

Após tratamos das motivações para a criação da BPB, a seguir, apresentaremos um mapeamento da formação do acervo base da Instituição, a partir dos dados que compulsamos no Idade d'Ouro do Brazil.

\subsection{Traços e percursos da formação do acervo da Biblioteca Pública da Bahia}

Com base nas pesquisas que temos desenvolvido acerca das práticas biblioteconômicas, sobretudo no século XIX, poderíamos estabelecer uma série de aproximações sobre o processo de gerenciamento da BPB. No entanto, no âmbito desse artigo, não haveria espaço para essas discussões.

A formação do acervo foi perscrutada a partir do Plano para o estabelecimento de uma bibliotheca pública na cidade de Salvador, oferecido a aprovação do Sr. Conde dos Arcos, capitão general daquela capitania. É nele que Gomes Ferrão determinou as linhas que traçariam todo o modus operandi da Biblioteca em seus primeiros anos.

Vale chamar a atenção do leitor para o conteúdo a seguir. Nele, poderemos ver a preocupação em formalizar, de pronto, os critérios que norteariam a formação e desenvolvimento do acervo. Gomes Ferrão estabeleceu uma comissão - no caso, em sistema de rodízio - que seria responsável pela seleção dos títulos; e ainda primou para pela necessidade de um bibliotecário ${ }^{23}$. Por fim, não se pode esquecer que o grupo inicial de gestores dessa biblioteca produziu o primeiro catálogo de uma biblioteca brasileira.

O Plano priorizou aquisição de periódicos, a aquisição de livros ficou em segunda prioridade. O texto descreve os procedimentos para a circulação desse item do acervo, assim como o modo de gerenciamento.

Far-se-ha um Fundo por subscripção, para se mandarem vir de Londres, e de quaesquer outros Paizes q tiverem relação

\footnotetext{
${ }^{22}$ Nossa leitura acerca dos conceitos de grupo e civilização partem de Nobert Elias, sobretudo nas obras: ELIAS, N. O processo civilizador. Rio de Janeiro: Jorge Zahar, 1994. 2v. e ELIAS, N. A sociedade dos indivíduos. Rio de Janeiro: Jorge Zahar, 1994.

${ }^{23} \mathrm{Em}$ pesquisa finalizada em 2008, fizemos uma aproximação acerca das prática de seleção e aquisição do século XIX com as recomendações modernas, tendo como objeto de análise o Gabinete Português de Leitura. AZEVEDO, F. C. de. A política de seleção do Real Gabinete Português de Leitura: identificação a partir da compilação de Atas e Relatórios do período de 1837-1847. 2007. 117f. Monografia (Graduação em Biblioteconomia). Universidade Federal do Estado do Rio de Janeiro. 2007. Disponível em: <http://eprints.rclis.org/13909/>. Acesso em: 7 nov. 2009.
} 
com esta Cidade, os Periodicos de melhor reputação litteraria, de mais ampla instrucção. Estes virão remettidos a qualquer dos Censores da Typographia desta Cidade, que a rogo dos Subscriptores quizer servir a Publico, com ausencia aos outros, e por elle abertos, e comunicados ao Governador donde passarão á casa para em fim destinada, e nella estarão patentes, por espaço de tres dias a exame e leitura q qualquer dos assignantes quizer nelles fazer, e passados este termo poderão pedir, e ver-Ihes-ha confiado um dos ditos Periodicos, ou Folhas por tempo de vinte e quatro horas prefixas, deixando recibo á pessoa encarregada da sua guarda, e conservação, e depois de vistas, serão recolhidas em uma Estante fechada, e não se darão a ler, senão aos assignantes, e na mesma casa, quando por estes forem pedidos.

O fato de tratar da aquisição de livros, após normatizar os periódicos, não significa somenos. De certo que o processo de compra de livros devia requerer uma atenção e cuidado especiais, afinal, apesar das liberalidades advindas desse período de "Idade d'Ouro", ainda estávamos sob o julgo da censura ${ }^{24}$.

De acordo com Plano de Gomes Ferrão, pelo menos nos primeiros anos da BPB, os subscritores deveriam ser convocados a cada três meses para realizar a seleção dos livros. Essa convocatória poderia ser feita pelo Idade d'Ouro, como esse de 10 de novembro de 1812, à guisa de exemplo:

\section{Aviso}

Participa-se aos Senhores Subscriptores da Livraria Pública desta Cidade, que no dia 11 do corrente pelas 11 horas da manha se há de fazer a Secção do costume, e roga-se queirão concorrer á ella.

Os livros deveriam vir da Europa, porque, naquela primeira década do século XIX ,não havia meios de compra na cidade de Salvador. Observa-se, também, do trecho abaixo, que a forma prevista para o funcionamento era muito próxima dos modelos associativos:

Para escolha dos Livros, q se devem mandar vir da Europa, haverá de trez em trez mezes uma Sessão dos Subscriptores q

\footnotetext{
${ }^{24}$ Acerca desse período, dentre várias fontes de igual relevância, recomendamos: ABREU, M. O controle à publicação de livros nos séculos XVIII e XIX: uma outra visão da censura. Revista de História e Estudos Sociais, São Paulo, v. 4, n. 4, out.-dez., 2007, p. 1-12. Disponível em: <http://www.revistafenix.pro.br/PDF13/DOSSIE \%20ARTIGO 02-Marcia Abreu.pdf>. Acesso em: 12 ago. 2011.

NEVES, L. M. B. P. das; FERREIRA, T. M. T. B. da C. O medo dos "abomináveis princípios franceses": a censura dos livros nos inícios do século XIX no Brasil. Acervo, Rio de Janeiro, v. 4, n. 1, jan-jun., 1989, p. 113-119. Disponível em: <http://www.historiacolonial.arquivonacional.gov.br/media/omedo.pdf>. Acesso em: 12 ago. 2011.
} 
se acharem presentes, a qual será presidida pelo Censor, e cada um delles poderá lembrar os livros que bem Ihe parecer dando a razão da sua escolha, e depois de ouvidos, e tomados os apontamentos necessarios nomear-se-hão dois Socios, com os quaes o Censor fará a lista das encommendas á proporção dos Fundos do Estabelecimento ${ }^{25}$.

O Idade d'Ouro do Brazil foi o meio de divulgação da BPB, e no dia 13 de Agosto de 1811 informa que os subscritores que já acorriam ao acervo, atendendo a anúncio anterior. O texto destaca a solicitação para inscrição de subscritores e para doação de livros.

Não são somente os Indigenas, e os Nacionaes, que subscrevem para o fundo da Livraria com dinheiro, e offerecem os seus livros para a instrucção publica, são Estrangeiros em grande numero, que mostrão a mesma cordialidade para comnosco, e sacrificio voluntaries dinheiro, e livros, e até se impoem o ónus perpetuo d'huma annuidade. Devia-se este testemunho público á sua beneficiencia, e a Idade de Ouro desempenha assim hum dos deveres, que annunciara no seu prospecto.

De certo que a maneira de aquisição de livros em Salvador, assim como nas cidades do Rio de Janeiro e São Paulo, nessa primeira década do século XIX, não era fácil com a presença de livrarias. Por essa razão, a diretoria da Biblioteca solicitou à população de Salvador a disponibilização de livros novos ou em bom uso para compra, a fim de aumentar ao acervo.

Compulsamos alguns números do Idade d'Ouro e identificamos doações de livros e bibliotecas de particulares, assim como adesões de subscritores que aquiesceram ao projeto do estabelecimento da Biblioteca Pública. Percebemos algumas categorias de doações, como: "alguns livros"; "E todos os seus livros em doação perpetua"; "doação perpétua"; "Offerece todos os seus livros [...] por todo o tempo do seu Governo; "offerece alguns volumes durante sua residencia nesta Cidade"; "E emprestará todos os livros, que puder se usar"; "Dará alguns livros dos poucos que tem", dentre outras.

A quantia em dinheiro para subscrição anual estabelecida pelo Plano era de $10 \$ 000$. A lista, a seguir, mostra que, já antes desse anúncio, havia os que ocorreram a BPB para oferecer doações e aderir como subscritor.

\footnotetext{
${ }^{25}$ Fugindo do escopo desse artigo, mas a partir de pesquisa que desenvolvemos anteriormente, seria perfeitamente possível traçar um paralelo com as medidas adotadas pelos Real Gabinete Português de Leitura em 1837.
} 
Nessa lista, aparecem as doações de livros, que podiam ser de apenas um volume, como no caso do sr. Joaquim Joaquim da Silva Guimarães; "alguns livros", como fez o sr. João Rodrigues de Brito.

Tabela 1 - Subscripção para o estabelecimento da Livraria Publica

\begin{tabular}{l|l|c}
\hline & Entrada & $\begin{array}{c}\text { Subscripção } \\
\text { annual }\end{array}$ \\
\hline $\begin{array}{l}\text { O Illustrissimo, e Excellentissimo Senhor Conde dos } \\
\text { Arcos, Governador, e Capitão General. }\end{array}$ & $64 \$ 000$ \\
$\begin{array}{l}\text { Offerece todos os seus livros de História, Poesia e } \\
\text { materias amenas por todo o tempo do seu Governo. }\end{array}$ & \\
\hline $\begin{array}{l}\text { O Excellentissimo, e Reverendissimo Senhor Arcebispo } \\
\text { da Bahia }\end{array}$ & $50 \$ 000$ & $10 \$ 000$ \\
\hline A Excellentissima Condessa da Ponte & $30 \$ 000$ & $10 \$ 000$ \\
\hline $\begin{array}{l}\text { O Conselheiro Chanceller da Relação Antonio Luiz } \\
\text { Pereira da Cunha offerece alguns volumes durante sua } \\
\text { residencia nesta Cidade }\end{array}$ & $50 \$ 000$ & $10 \$ 000$ \\
\hline Felisberto Caldeira Brant Pontes & & $10 \$ 000$ \\
\hline Joaquim Ignacio de Sequeira Bulcão & $50 \$ 000$ & $10 \$ 000$ \\
\hline $\begin{array}{l}\text { João Rodrigues de Brito } \\
\text { E alguns livros }\end{array}$ & $30 \$ 000$ & $10 \$ 000$ \\
\hline Antonio Fructuoso de Menezes Dórea & $30 \$ 000$ & $10 \$ 000$ \\
\hline $\begin{array}{l}\text { João Joaquim da Silva Guimarães } \\
\text { Offerece huma edição de Historia Romana de Rolim }\end{array}$ & $32 \$ 000$ & $10 \$ 000$ \\
\hline Manoel Ignacio da Cunha e Menezes & $30 \$ 000$ & $10 \$ 000$ \\
\hline Antonio Brandão Pereira Marinho Falcão & $32 \$ 000$ & $10 \$ 000$ \\
\hline Bento de Araujo Lopes Villas-Boas & $20 \$ 000$ & $10 \$ 000$ \\
\hline José Joaquim Muniz Barreto & $30 \$ 000$ & $10 \$ 000$ \\
\hline Nicoláo Carneiro da Rocha e Menezes & $32 \$ 000$ & $10 \$ 000$ \\
\hline Manoel de Lima Pereira & $30 \$ 000$ & $10 \$ 000$ \\
\hline Antonio Joaquim Pires de Carvalho e Albuquerque & $20 \$ 000$ & $10 \$ 000$ \\
\hline $\begin{array}{l}\text { Manoel Ferreira de Andrade } \\
\text { Dará alguns livros }\end{array}$ & $64 \$ 000$ & $10 \$ 000$ \\
\hline Onte: IDADE d Ouro do Brazil. Bahia: & & \\
\hline
\end{tabular}

Fonte: IDADE d'Ouro do Brazil. Bahia: Na Typografia de Manoel da Silva Serva, 13 de Agosto de 1811, p. 3-4, n. 27. Acervo Biblioteca Digital Fundação Biblioteca Nacional.

Na edição de sexta-feira, dia 16, ficou registrado a doação de um dos maiores promotores da Instituição, Pedro Gomes Ferrão e a "doação perpétua" e feita pelo sr. Luiz Pereira Sodré:

Tabela 2 - Subscripção para o estabelecimento da Livraria Publica

\begin{tabular}{l|c|c}
\hline & Entrada & $\begin{array}{c}\text { Subscripção } \\
\text { annual }\end{array}$ \\
\hline Antonio Pedro da Silva Guimarães & $50 \$ 000$ & $10 \$ 000$ \\
\hline José Francisco Cardozo e Moraes & $25 \$ 600$ & $10 \$ 000$ \\
\hline Luiz Pereira Sodré & $32 \$ 000$ & $10 \$ 000$ \\
\hline $\begin{array}{l}\text { E todos os seus livros em doação perpetua } \\
\text { E todos Gomes Ferrão }\end{array}$ & $50 \$ 000$ & $10 \$ 000$ \\
\hline
\end{tabular}

Fonte: IDADE d'Ouro do Brazil. Bahia: Na Typografia de Manoel da Silva Serva, 16 de Agosto de 1811, p. 3, n. 28. Acervo Biblioteca Digital Fundação Biblioteca Nacional.

O resultado da pesquisa no Idade d'Ouro mostra que a população soteropolitana respondia favoravelmente. 
Na lista, a seguir, destaca-se a doação feita por Francisco Agostinho Gomes, sucessor de Gomes Ferrão Castelo Branco.

Tabela 3 - Subscripção para o estabelecimento da Livraria Publica

\begin{tabular}{l|c|c}
\hline & Entrada & $\begin{array}{c}\text { Subscripção } \\
\text { annual }\end{array}$ \\
\hline $\begin{array}{l}\text { Joaquim Anselmo Alves Branco Muniz Barreto } \\
\text { E todos os seus livros durante a sua residencia } \\
\text { nessa Cidade }\end{array}$ & $32 \$ 000$ & $10 \$ 000$ \\
\hline Francisco Gomes de Souza & $32 \$ 000$ & $10 \$ 000$ \\
\hline José Agostinho de Sales & $20 \$ 000$ & $10 \$ 000$ \\
\hline Francisco Agostinho Gomes & $25 \$ 600$ & $10 \$ 000$ \\
E emprestará todos os livros, que puder se usar & $40 \$ 000$ & $10 \$ 000$ \\
\hline Domingos José Antonio Rebello & $64 \$ 000$ & $10 \$ 000$ \\
\hline Antonio José Gomes & $25 \$ 600$ & $10 \$ 000$ \\
\hline Ignacio José Aprigio da Fonseca Galvão & & $10 \$ 000$ \\
\hline Dará alguns livros dos poucos que tem. & $12 \$ 800$ & $10 \$ 000$ \\
\hline José Teixeira da Matta Bacellar & $20 \$ 000$ & $10 \$ 000$ \\
\hline Antonio Manoel de Mello e Castro & $32 \$ 000$ & \\
\hline Antonio José d'Almeida & Manoel da & \\
\hline
\end{tabular}

Fonte: IDADE d'Ouro do Brazil. Bahia: Na Typografia de Manoel da Silva Serva, 20 de Agosto de 1811, p. 3-4, n. 29. Acervo Biblioteca Digital Fundação Biblioteca Nacional.

É necessário pontuar que, afora o possível "status" de contribuir publicamente para o desenvolvimento de uma instituição cultural, poderíamos inferir que o fato do sr. Ignacio José Aprigio da Fonseca Galvão estar disposto a dar "alguns livros dos poucos que tem" revelaria a adesão e esforço para o sucesso novo empreendimento.

Tabela 4 - Subscripção para o estabelecimento da Livraria Publica

\begin{tabular}{l|c|c}
\hline & Entrada & $\begin{array}{c}\text { Subscripção } \\
\text { annual }\end{array}$ \\
\hline Luiz de Barros Teixeira Lobo & $20 \$ 000$ & $10 \$ 000$ \\
\hline João de Mello Lene Cogominho de Lacerda & $20 \$ 000$ & $10 \$ 000$ \\
\hline José Rodrigues de Figueiredo Junior & $25 \$ 000$ & $10 \$ 000$ \\
\hline O Thesoureiro Mór José Félix de Menezes & $32 \$ 600$ & $10 \$ 000$ \\
\hline $\begin{array}{l}\text { Manoel José de Mello } \\
\text { Offerece por emprestimo os seus livros }\end{array}$ & $25 \$ 600$ & $10 \$ 000$ \\
\hline José Avellino Barbosa & $12 \$ 800$ & $10 \$ 000$ \\
\hline João Lourenço Barbosa & $32 \$ 800$ & $10 \$ 000$ \\
\hline Gonçalo Vicente Portella & $20 \$ 800$ & $10 \$ 000$ \\
\hline José Venancio de Seixas & $34 \$ 000$ & $10 \$ 000$ \\
\hline $\begin{array}{l}\text { Henrique Hill } \\
\text { Offerece alguns Livros Inglezes, que tem, pelo } \\
\text { tempo da residencia na Bahia }\end{array}$ & $32 \$ 000$ & $10 \$ 000$ \\
\hline $\begin{array}{l}\text { O Physico Mór Delegado José Antonio Costa } \\
\text { Ferreira }\end{array}$ & $16 \$ 000$ & $10 \$ 000$ \\
\hline Pedro Alexandrino de Souza Portugal & $20 \$ 000$ & $10 \$ 000$ \\
\hline $\begin{array}{l}\text { Cypriano Dionysio da Silva Souza e Azevedo } \\
\text { Offerece alguns livros }\end{array}$ & $12 \$ 000$ & $10 \$ 000$ \\
\hline
\end{tabular}

Fonte: IDADE d'Ouro do Brazil. Bahia: Na Typografia de Manoel da Silva Serva, 27 de Agosto de 1811, p. 3-4, n. 31. Acervo Biblioteca Digital Fundação Biblioteca Nacional. 
Como confirma Augel (1975), o fluxo de estrangeiros em Salvador era muito grande. Na lista anterior, vemos o sr. Henrique Hill oferecer seus livros de língua inglesa ao uso, enquanto residir na cidade.

O processo de doação continuou para além no ano de fundação da Biblioteca. Tanto, assim, que localizamos uma doação noticiada no Idade d'Ouro do Brazil de sexta-feira, 10 de abril de 1812

Clemente Ferreira França, Dezembargador da Supplicação do Brazil, e Ouvidor de Pernambuco, movido dos sentimentos patrioticos, que o distigue, pelo bem do Estado, e desejando concorrer para o desta Cidade, sua Patria, fez doação de $50 \$ 000$ reis em dinheiro, e de 38 volumes de diversas obras de merecimento, a beneficio da Livraria pública desta, o que se dá a saber, em signal de gratidão, e em observancia dos Estatutos da mesma Livraria.

Ademais, seguindo o que estava estabelecido pelo Plano, a própria Biblioteca adquiria os livros a partir de encomendas que fazia na Europa, como se nota a partir do que foi publicado no Idade d'Ouro de 16 de junho de 1812 .

A relevância de identificar o apoio que os cidadãos da cidade do Salvador - como era chamada na época - subjaz na constatação de um desejo de ilustração que já vinha de longa data. O exemplo a seguir, publicado no Idade d'Ouro do Brazil de 8 de novembro de 1811, revela que até mesmo os baianos que não residiam na capital, de alguma maneira, buscaram dar seu apoio

Entende-se mais depressa como hum acto de Justiça, do que de Gratidão publicar a maneira nobre, e graciosa, com que Manoel Ribeiro Guimarães natural desta Cidade, morador em Londres se encarregou da remessa dos Livros para essa Livraria pública da Bahia sem outro qualquer interesse, ou commissão, que o de ser comtemplado no numero dos Subscriptores, oferecendo-se de mais a mais para enviar promptamente todas as encommendas seja qual for seu importe, e para contribuir ainda a favor daquelle útil Estabelecimento com a somma, que for compatível com as suas possibilidades.

Ainda mais surpreendente foi a generosidade do comerciante lisboeta José de Mello, que se ofereceu para enviar livros para a Biblioteca, como podemos ler no Supplemento Extraordinário, de quartafeira, 8 de janeiro de 1812 :

Seria huma falta de Justiça, e até de gratidão deixar, de publicar a nobre, e generosa Liberalidade com que José de Mello Negociante de Lisboa, se offerece a enviar da mesma Cidade todas as remessas de Livros que Ihe forem pedidos para a Livraria pública da Bahia, sem que para o fazer queira receber qualquer interesse, ou Commissão alguma sendo os Livros que se mencionão parte da primeira encommenda que se lhe fez por se não poder apromptar a outra parte; cuja Receita veio conduzida pelo Navio Santo Estevão, de que também o seu Correspondente, debaixo das mesmas vistas, 
Manoel de Menezes, natural de Baçaum generosamente não quis frete algum $[\ldots]$.

Algumas Instituições soteropolinas publicavam as prestações de conta no Idade. Prescrutanto o periódico, localizamos duas ocasiões nas quais a Biblioteca prestou conta publicamente aos seus subscritores. Identificamos duas prestações de conta, uma na edição de sexta-feira de 6 de março de 1812 e, a segunda, em 1814.

Como foi estabelecido pelo Plano, a BPB reservava uma grande quantia de verba à compra de itens para formação do acervo. Em 16 de dezembro de 1814, publicaram outra prestação de conta, um pouco mais detalhada.

O acervo da BPB e sua história seguiram seu percurso, com os momentos promissores e outros menos, como qualquer outra instituição. As doações de livros também prosseguiram. Knauss (2001) é o único a mencionar que além de livros houve doações de quadros, como os 37 do colecionador Antonio José Alves, em 1858.

Os relatos dos viajantes - como compilados e destacadas por Augel (1975) - revelam um bom panorama de como o acervo seguiu. E, ainda, apontam para endossar a presença de uma cultura letrada em Salvador, que se consolidou nas décadas da primeira metade do século XIX. De fato, a Biblioteca Pública da Bahia se tornara um importante espaço de leitura e circulação de livros e ideias, como queria Gomes Ferrão.

\section{Considerações finais}

No âmbito da História do Livro e das Bibliotecas no Brasil, perquirir ações atinentes à criação e formação dessa biblioteca, justifica-se por recuperar e trazer a lume uma série de documentos que estavam silentes.

O conceito de "lugares de memória", de Pierre Nora (1993), oscila entre simbólica e significação da documentação que localizamos. O incêndio causado pelo bombardeio, em 1912, causou perda do acervo bibliográfico, assim como de uma grande quantidade de documentos - a partir do que relatam as fontes que perquirimos na investigação.

A primeira fase dessa pesquisa, não obstante os percalços naturais, foi concluída, pois conseguimos localizar e consolidar uma grande quantidade de documentos que contribuem para narrar a história dessa Biblioteca. Nosso objetivo igualmente foi alcançando, uma vez que essas fontes revelam detalhes minuciosos da formação do acervo e da maneira de gerenciamento.

Este artigo representa o primeiro produto dessa pesquisa, que continuará agora a explorar outras facetas do conjunto documental, como, por exemplo, os catálogos. 
Os dados referentes às doações foram reveladores, porque confirmaram duas inferências constantemente feitas por alguns pesquisadores: havia livros circulando entre soteropolitanos e uma forte influência iluminista permeava a elite intelectual da cidade.

Esta pesquisa, com seus aspectos arqueológicos, além de mapear o processo de criação da BPB, pôde, igualmente, constituir um corpus teórico que permitirá a outros pesquisadores seguirem em outros caminhos.

Pelos resultados que alcançamos ao percorrer o Idade d'Ouro do Brazil, fica ainda mais patente que, além dos inventários por mortem, a pesquisa em periódicos é um excelente meio de identificar circulação, posse e consumo de livros ${ }^{26}$.

Sem dúvida alguma, cremos que se entendêssemos alguns deslocamentos do passado, no presente, poderíamos perceber como certos conceitos foram se perdendo. Atualmente percebemos que certas discussões acerca da missão da Biblioteca Pública no Brasil e todas as ponderações - que não caberiam aqui - seriam muito mais profícuas, se por uma compilação de conceitos.

Os resultados desta pesquisa, apesar de satisfatórios, demonstraram que é preciso analisar outras facetas da formação dessa Biblioteca e avançar para as décadas que não estavam em nosso recorte cronológico, analisando seus catálogos e perscrutando os periódicos da época, a fim de mapear os fatos históricos referentes à coleção. Para os estudos acerca das bibliotecas públicas, talvez uma contribuição foi a de demonstrar como se pensava em Formação e Desenvolvimento de Coleções para esse tipo de biblioteca e algumas práticas biblioteconômicas previstas para concluir essa atividade.

Uma vez que este projeto esteve vinculado ao grupo de pesquisa que fazemos parte na UNIRIO, estabelecemos diálogos com outros colegas que pesquisam bibliotecas públicas ${ }^{27}$.

Esta pesquisa confirma a significância do século XIX como consolidador de meios legitimados para circulação de impressos no Brasil, também fora do eixo Rio de Janeiro, São Paulo e Minas Gerais.

Em um momento no qual as Bibliotecas Públicas são fechadas ou "substituídas", cremos que deveríamos promover debates e discussões sobre o que se pensou um dia desse tipo de biblioteca - como foi exaustivamente descrito nas linhas precedentes.

26 Sobre este tema, recomendamos: FERREIRA, T. M. T. B. da C. Palácio de destinos cruzados: homens e livros no Rio de Janeiro, 1870-1920. Rio de Janeiro: Arquivo Nacional, 1999. $240 \mathrm{p}$.

Nomeadamente as professoras Maura Esandola Quinhões, Elisa Machado e Daniele Achilles. 
À guisa de conclusão, pedimos desculpas ao leitor para repetir aqui parte da primeira citação desse artigo, por ver nele uma chave de reflexão: "A instituição das Bibliothecas Publicas é uma das mais importantes ações que o progresso humanitário tem realizado $[\ldots]$ "

\section{Referências}

APONTAMENTOS que podem interessar a publicação da Corograhia Historica. [S.I.: s. n., s.d.]. [documento manuscrito]. (Acervo FBN Ms: I $32,13.1$ n. 2).

AUGEL, M. P. Visitantes estrangeiros na Bahia oitocentista. $285 \mathrm{f}$. Dissertação (Mestrado em História) - Universidade Federal da Bahia, Salvador, 1975.

BATTLES, M. A conturbada história das bibliotecas. São Paulo: Planeta, 2003.

BIBLIOTECA Pública da Bahia. [S.I.: s. n., s.d.]. [documento manuscrito]. (Acervo FBN Ms: I 32, 13.1 n. 1).

BLUTEAU, Raphael. Vocabulario portuguez \& latino: aulico, anatomico, architectonico ... Coimbra: Collegio das Artes da Companhia de Jesu, 1712 - 1728. 8 v. Disponível em: <http://www.brasiliana.usp.br/dicionario/edicao/1>. Acesso: 8 maio 2011.

BURKE, P. A Escola dos Annales: 1929-1989. São Paulo: UNESP, 1997.

CAMPELLO, B. S.; ANDRADE, M. E. A. Fontes de informação para bibliotecas públicas e comunitárias brasileiras: proposta para seu estudo nos cursos de Biblioteconomia. R. Esc. Bibliotecon, Belo Horizonte, v. 17, n. 2, p. 173-185, 1988.

CATALOGO dos livros que se acham na Livraria Pública da cidade da Bahia em maio de 1818. [documento manuscrito]. (Acervo FBN 01, 1, 026)

CATALOGO dos livros que se achão na Bibliotheca publica da cidade da Bahia.[ Bahia: Na Typographia de Manoel Antonio da Silva Serva, 1818].

CASTELO BRANCO, P. G. F. Plano para o estabelecimento de uma bibliotheca pública na cidade de Salvador, oferecido a aprovação do Sr. Conde dos Arcos, capitão general daquela capitania. [S.I.: s. n., s.d.]. (Acervo FBN I-32,13,001 n. 001-003)

- Discurso recitado na sessão de abertura da Livraria Publica da Bahia no dia 4 de agosto de 1811 / por seu autor P.G.F.C. Bahia: Na Typographia de Manoel Antonio da Silva Serva, [1811].

- Plano para o estabelecimento de huma bibliotheca publica na cidade de S. Salvador [...]. [Bahia :, Na Typographia de Manoel Antonio da Silva Serva,,1811].

CIM, A. Une bibliothèque: l'art d'acheter les livres, de les classes, de les conserver et de s'en servir. Paris: E. Flammarion, 1902. 
COUSIN, J. De l'organisation et d'administration des bibliothèques publiques et privées: Manuel théorique \& pratique du bibliothécaire. Paris: A. Durant et Pedone-Lauriel, 1882. p. VII.

DEAECTO, M. M. No império das letras: instituições e práticas de leitura na São Paulo oitocentista. São Paulo: Edusp; Fapesp, 2011.

ELIAS, N. O processo civilizador. Rio de Janeiro: Jorge Zahar, 1994. 2v. A sociedade dos indivíduos. Rio de Janeiro: Jorge Zahar, 1994.

HALLEWELL, L. O livro no Brasil: sua história. São Paulo: EDUSP, 1982.

. O livro no Brasil: sua história. São Paulo: EDUSP, 2005.

IDADE d'Ouro do Brazil. Bahia: Na Typografia de Manoel da Silva Serva, n. $28 ; 29 ; 31-33 ; 35 ; 52$, 1811. (Acervo FBN)

- Bahia: Na Typografia de Manoel da Silva Serva, 8 de janeiro de 1812. Supplemento Extraordinário.

. Bahia: Na Typografia de Manoel da Silva Serva, de 29 de fevereiro de 1812. Supplemento Extraordinário.

. Bahia: Na Typografia de Manoel da Silva Serva, n. 19; 43; 46; 48; $62 ; 87 ; 88 ; 90,1812$.

. Bahia: Na Typografia de Manoel da Silva Serva, n. 10, 1813.

Bahia: Na Typografia de Manoel da Silva Serva, n. 100, 1814.

KNAUSS, P. O cavalete e a paleta: arte e prática de colecionar no Brasil. Anais do Museu Histórico Nacional, Rio de Janeiro, v. 33, p. 25-44, 2001. Disponível em: <http://www.historia.uff.br/labhoi/files/May07HQ6 MUcT cavalete paleta.pdf>. Acesso em: 7 nov. 2008.

LASSO DE LA VEGA, J. Manual de biblioteconomia: organizacion tecnica y cientifica de las biblioteca. Madrid: Mayfe, 1952.

LE GOFF, J. Documento/Monumento. In: - História e memória. Campinas: Editora da Unicamp, 2010.

LESSA, C. R. As bibliotecas brasileiras dos tempos coloniais: apontamentos para um estudo histórico. Rev. IHGB, Rio de Janeiro, v. 191, p. 339-345, abr./jun. 1946.

MACIEL, A. C.; MENDONÇA, M. A. R. Bibliotecas como organizações. Rio de Janeiro: Interciência, 2000.

MARTINS, W. A palavra escrita: história do livro, da imprensa e da biblioteca. 3. ed. São Paulo: Ática, 2001.

MORAES SILVA, Antonio. Diccionario da lingua portugueza. Lisboa: na Typographi a Lacerdina, 1813, 2v. Disponível em: http://143.107.31.231/catalogo eletronico/consultaDocumentos.asp?Tipo Consulta= Acervo\&Acervo Codigo=2\&Setor Codigo=11.: Acesso: 8 maio 2011. 
MORAES, R. B. de. Livros e bibliotecas no Brasil colonial. Rio de Janeiro: LTC; São Paulo: Secretaria de Cultura,Ciência e Tecnologia, 1979.

2006.

. Livros e bibliotecas no Brasil colonial. Brasília: Briquet de Lemos,

MOTTA e SILVA, B. Cidade de Salvador: caminho e encantamento. São Paulo: Companhia Editora Nacional, 1958.

MUNIZ, A. F. (Org.). Catalogo geral das obras de sciencias e litteratura que contem a Bibliotheca Publica da provincia da Bahia [...]. Bahia: Typ. Constitucional, 1878. (Acervo FBN).

. Catalogo geral das obras de sciencias e litteratura que contem a Bt. Publ. da Bahia organizado pelo seu bibliotecario Antonio Ferrão Muniz. Bahia: Typ. Constitucional, 1883. (Acervo FBN).

NAUDÉ, G. Advis pour dresser une bibliothèque... Paris: F. Targa, 1627.

NORA, P. Entre memória e história: a problemática dos lugares. Projeto História. Revista do programa de estudos pós-graduados em História e do Departamento de História, São Paulo, n. 10, p. 1-78, dez. 1993.

PEIGNOT, G. Manuel du bibliophile, ou traité du choix des livres... Dijon: chez Victor Lagier Libraire, 1828.

PEIXOTO, A. Breviário da Bahia. Rio de Janeiro: Agir, 1946.

PETZHOLDT, G. Manuale del bibliotecário. Milano: Vecchiarelli, 1894.

PINHEIRO, A. V. Organização e administração de bibliotecas: planos de aula. Rio de Janeiro, 2007. (Apostila de aula).

PRADO, $H$. de A. Aquisição e seleção de material. In:

Organização e administração de bibliotecas. 2. ed. rev. São Paulo: T. A. Queiroz, 1992. p. 26-29.

REBELO, C. A. As instituições de leitura. In: A difusão da leitura pública: as bibliotecas populares, 1870-1910. Porto: Campo das Letras, 2002. p. 69-107.

SÁ, J. de. O bombardeiro da Bahia e seus efeitos: registro político e histórico. Bahia: Officinas do "Diário da Bahia", 1918 apud MOTTA e SILVA, B. Cidade de Salvador: caminho e encantamento. São Paulo: Companhia Editora Nacional, 1958.

SERAFIM LEITE. História da Companhia de Jesus no Brasil. Rio de Janeiro: Imprensa Nacional, 1945. Tomo V.

SILVA, M. B. N. da. A Livraria Pública da Bahia em 1818: obras de história. Revista de História, São Paulo, v. 43, n. 87, p. 225-239, 1971.

. Entrevista. Revista Acervo, Rio de Janeiro: Arquivo Nacional, v. 21, p. 3-7, jan./jun. 2008.

SILVA, A. M. Diccionario da lingua portugueza [recompilado dos vocabularios impressos ate agora, e nesta segunda edição novamente 
emendado e muito acrescentado]. Lisboa: Typographia Lacerdina, 1813. Disponível em: <http://www.brasiliana.usp.br/dicionario/edicao/1>. Acesso: 8 maio 2011. 